\title{
Zuschriften
}

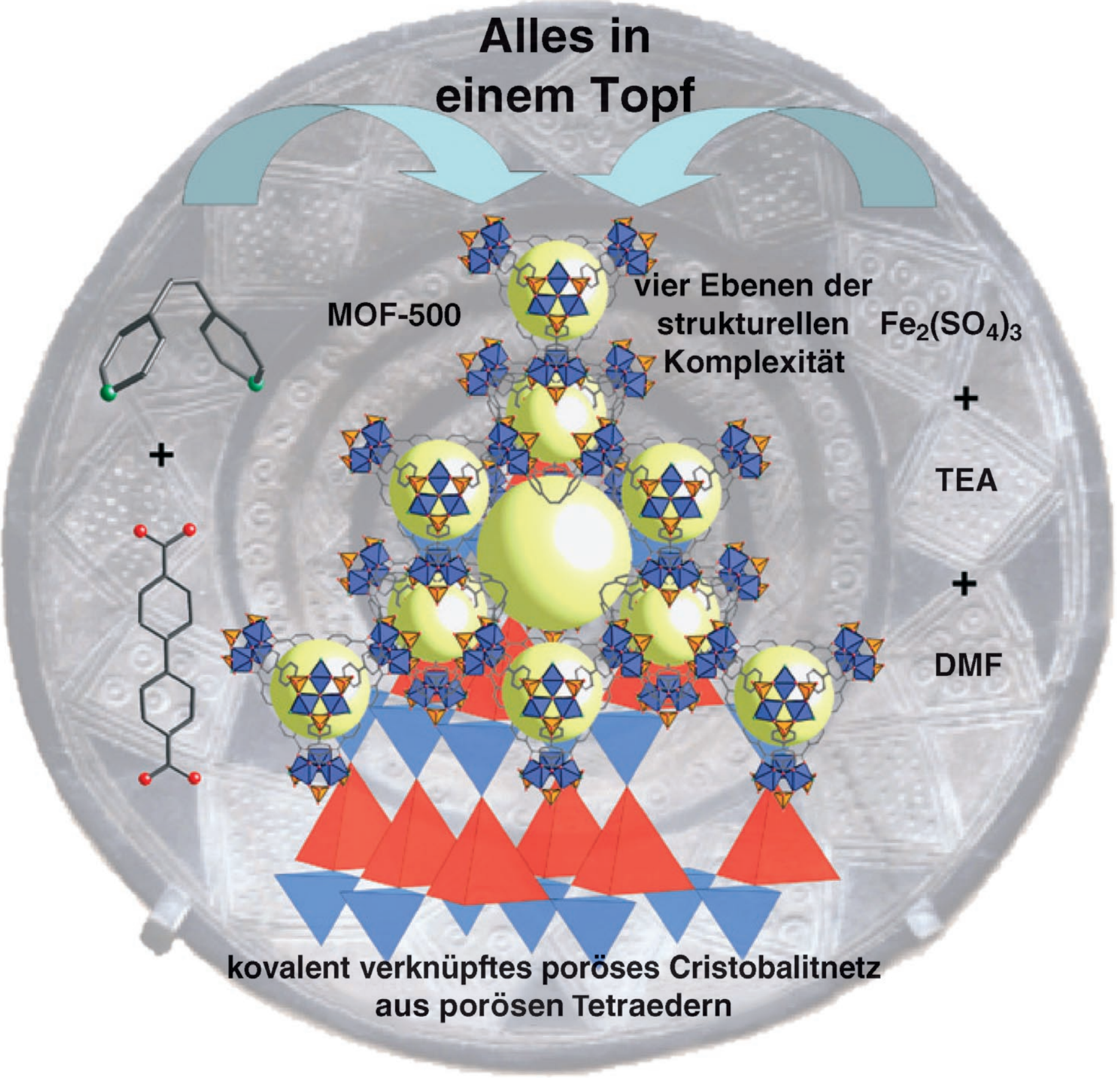

Die stufenweise Synthese hierarchischer Festkörperstruktu-

ren wird durch die Unlöslichkeit der Intermediate erschwert. O. M.

Yaghi et al. beschreiben in ihrer Zuschrift auf den folgenden Seiten, wie das metall-organische Gerüst MOF-500 auf der Grundlage der Kristallstruktur seiner porösen tetraedrischen Bausteine konzipiert und in einer Eintopfsynthese hergestellt wurde. 
DOI: $10.1002 /$ ange. 200600175

\section{A Metal-Organic Framework with a Hierarchical System of Pores and Tetrahedral Building Blocks**}

\author{
Andrea C. Sudik, Adrien P. Côté, Antek G. Wong-Foy, \\ Michael O'Keeffe, and Omar M. Yaghi*
}

Hierarchical chemical structures that incorporate some of the complexity typical of biological assemblies now exist and are being developed for use as highly selective catalysts, sensors, and ion- and drug-transport materials. Generally, such synthetic systems are based on supramolecular structures, for which it is possible to design step-by-step reactions that progressively lead to complex architectures of discrete molecular components. ${ }^{[1]}$ In contrast, the stepwise synthesis of analogous extended (nonmolecular) networks is not feasible, because the intermediates are insoluble. Herein, we present the synthesis of MOF-500, a new metal-organic framework (MOF), to illustrate how a "one-pot" reaction can yield a crystalline solid with four distinct levels of complexity (defined by structural elements of increasing size, with distinct compositions, structures, and pores). Prior knowledge of reaction conditions that yield the porous tetrahedral level-3 building blocks of MOF-500 (Figure 1) obviates the need for a multistep synthesis. ${ }^{[2]}$ We highlight the remarkable similarities between the structure of the extended network MOF-500 and that of its molecular building blocks (IRMOP-51). Furthermore, we demonstrate that a concomitant fourfold increase in gas uptake and surface area occurs on going from the crystals of the molecular building blocks IRMOP-51 to those of the extended network MOF-500.

Figure 1 outlines the conceptual and practical aspects of the synthesis and structure of MOF-500, in the context of four

[*] Dr. A. P. Côté, Prof. O. M. Yaghi

Department of Chemistry and Biochemistry

University of California, Los Angeles

Los Angeles, CA 90095-1569 (USA)

Fax: (+1) 310-206-4038

E-mail:yaghi@chem.ucla.edu

Dr. A. C. Sudik, Dr. A. G. Wong-Foy

Materials Design and Discovery Group

Department of Chemistry, University of Michigan

Ann Arbor, MI 48109-1055 (USA)

Prof. M. O'Keeffe

Department of Chemistry and Biochemistry

Arizona State University, Tempe, AZ 85287-1604 (USA)

[**: This work was supported by the National Science Foundation (DMR 0242630) and the Department of Energy (DOE). We thank Dr. Matthias Thommes from Quantachrome Instruments for helpful discussions concerning DFT calculations and Mr. Andrew R. Millward for assistance in adsorption studies. A.P.C. thanks the Natural Sciences and Engineering Research Council of Canada (NSERC) for a postdoctoral fellowship.

0 Supporting information for this article is available on the WWW under http://www.angewandte.org or from the author.

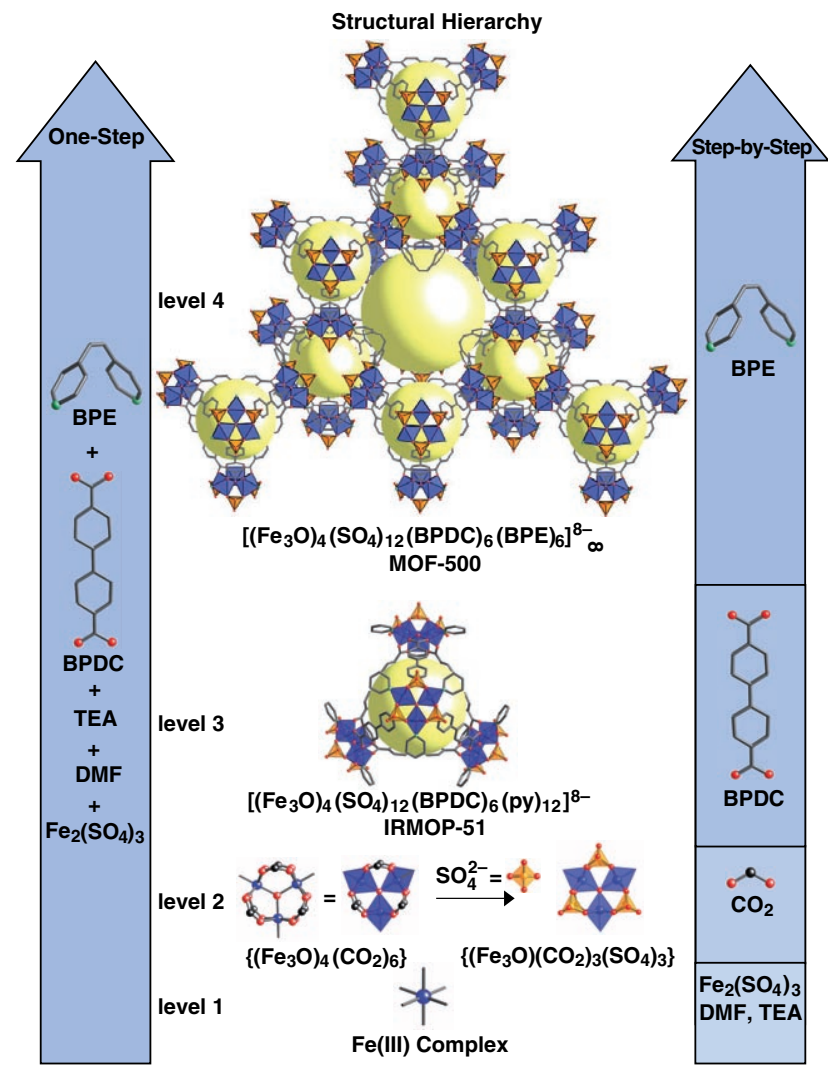

Figure 1. Conceptual representation of the synthesis and hierarchical structure of MOF-500. MOF-500 is built up from four distinct levels of structural hierarchy. Progression from one level to the next proceeds with the addition of a linking component. Although the step-by-step assembly (right arrow) of MOF-500 is not feasible in practice, a onestep synthesis (left arrow) is successful. See text for details. Fe blue atoms and polyhedra, $\mathrm{S}$ orange polyhedra, $\mathrm{O}$ red, $\mathrm{N}$ green, $\mathrm{C}$ gray; yellow spheres represent the tetrahedral pore space. Hydrogen atoms and the minor disorder components of the BPDC linkers are omitted.

levels of increasing complexity. Dissolution of $\mathrm{Fe}_{2}\left(\mathrm{SO}_{4}\right)_{3}$ in $N, N^{\prime}$-dimethylformamide (DMF) and triethylamine (TEA) yields solvated $\mathrm{Fe}^{\mathrm{III}}$ ions (level 1), which in the presence of carboxylates, aggregate into trigonal $\left\{\left(\mathrm{Fe}_{3} \mathrm{O}\right)\left(\mathrm{CO}_{2}\right)_{3}\left(\mathrm{SO}_{4}\right)_{3}\right\}$ units (level 2) ${ }^{[2]}$ In the absence of the sulfate capping groups, each of these units has six carboxylate ligands, $\left\{\left(\mathrm{Fe}_{3} \mathrm{O}\right)-\right.$ $\left.\left(\mathrm{CO}_{2}\right)_{6}\right\}$, and can be viewed as a trigonal-prismatic building block. Such metal-carboxylate trigonal-prismatic units can be joined by multitopic organic linkers to form MOFs at the next level of structural hierarchy (level 3). ${ }^{[3-5]}$ For example, Férey and co-workers used structural hierarchy to computationally predict and subsequently synthesize a series of highly porous MOFs (MIL-100, MIL-101, MIL-hypo-1, and MIL-hypo-2) based on trigonal-prismatic $\left\{\left(\mathrm{Cr}_{3} \mathrm{O}\right)\left(\mathrm{CO}_{2}\right)_{6}\right\}$ units and 1,4benzenedicarboxylate or 1,3,5-benzenetricarboxylate linkers. ${ }^{[6]}$ We have recently shown that the sulfate-capped $\left\{\left(\mathrm{Fe}_{3} \mathrm{O}\right)\left(\mathrm{CO}_{2}\right)_{3}\left(\mathrm{SO}_{4}\right)_{3}\right\}$ units of level 2 can be joined by multitopic organic linkers (for example, 4,4'-biphenyldicarboxylate (BPDC)) in the presence of pyridine (py) to give the series of discrete porous tetrahedra IRMOP-51-53 at level 3. ${ }^{[2]}$ These compounds have the same topology and are, thus, termed isoreticular metal-organic polyhedra (IRMOP). In these 
IRMOP, three terminal pyridine ligands coordinate to each trigonal $\left\{\left(\mathrm{Fe}_{3} \mathrm{O}\right)\left(\mathrm{CO}_{2}\right)_{3}\left(\mathrm{SO}_{4}\right)_{3}\right\}$ unit. Herein, we use the level-3 compound IRMOP-51 as a building block for a fourth level of complexity, by replacing the pyridine ligands with a bipyridine linker, cis-1,2-bis-4-pyridylethane (BPE), to yield the extended network MOF-500. In so doing, four types of interconnected pores are created, which can be fully utilized for gas storage.

Conceptually, there are two pathways that can be employed to achieve the structure of MOF-500: a step-bystep addition of the required components or a one-pot reaction combining all components (Figure 1). The first strategy is difficult to implement in this system, because the level-3 compound IRMOP-51 is insoluble. Therefore, it was necessary to synthesize MOF-500 by the second strategy, by finding reaction conditions that combine all the steps.

The reaction conditions that produce MOF-500 are based on the procedure used to prepare the level-3 compound IRMOP-51. Equimolar amounts of $\mathrm{Fe}_{2}\left(\mathrm{SO}_{4}\right)_{3} \cdot x \mathrm{H}_{2} \mathrm{O}$ and $\mathrm{H}_{2}$ BPDC were heated $\left(100{ }^{\circ} \mathrm{C}, 24 \mathrm{~h}\right)$ in a solution of DMF, TEA, and BPE to afford orange crystals of MOF-500 (15\% yield, based on $\mathrm{H}_{2} \mathrm{BPDC}$; see Supporting Information). A single crystal selected from the resulting MOF-500 sample was analyzed using X-ray diffraction. ${ }^{[7]}$ FT-IR spectroscopy, thermogravimetric analysis (TGA), and powder X-ray diffraction (PXRD) were used to confirm the structural assignment and phase purity of the bulk sample (see Supporting Information). Elemental analysis revealed a formula of $\left[\left(\mathrm{Fe}_{3} \mathrm{O}\right)_{4}\left(\mathrm{SO}_{4}\right)_{12}(\mathrm{BPDC})_{6}(\mathrm{BPE})_{6}\right]^{8-} \cdot 8\left[\mathrm{NH}_{2}\left(\mathrm{CH}_{3}\right)_{2}\right]^{+} \cdot 13 \mathrm{H}_{2} \mathrm{O}$

$\cdot 8 \mathrm{DMF}$ for the as-synthesized crystals of MOF-500. The negative charge of the anionic MOF-500 framework ( -8 per formula unit) is balanced by eight dimethylammonium counterions, which are formed through the well-established decarbonylation of DMF upon heating in the presence of TEA. ${ }^{[8]}$ The cations are completely disordered in the crystal and, thus, difficult to locate using X-ray diffraction techniques. In addition, it is difficult to accurately determine the stoichiometry of the neutral guests (DMF and water), owing to their volatility, which can lead to changes in their stoichiometry during post-synthesis sample handling. Similar obstacles are commonly encountered in MOF chemistry. Nevertheless, given that the neutral guests will ultimately be evacuated or exchanged from the pores, and that the structure of the framework was determined definitively from the singlecrystal X-ray diffraction data, any ambiguity in the formulation of the guest molecules does not preclude the use of MOF500 as a porous material.

Generally, we and others have found that MOF crystals containing large guest-filled pores $(78.5 \%$ of the free volume (see Table 1 for definition) in MOF-500) diffract X-rays to a limited resolution (ca. $1 \AA$ ) and produce a large diffusescattering background, because of the liquid-like packing of the guest entities within the framework. ${ }^{[6 b, 9]}$ These factors do not inhibit the full and proper refinement of the metalorganic framework, as illustrated for MOF-5, ${ }^{[10]}$ but do make identification and refinement of the guests (solvent and cations) unfeasible. The final anisotropically refined model for MOF-500 $\left(R_{1}=0.1005, w R_{2}=0.2598\right)$ confirms that BPE molecules link the IRMOP-51 tetrahedra in the structure, as the assignment of atom types to electron-density peaks was unambiguous, and the average bond lengths and angles for the $\left\{\left(\mathrm{Fe}_{3} \mathrm{O}\right)\left(\mathrm{CO}_{2}\right)_{3}\left(\mathrm{SO}_{4}\right)_{3}\right\}$ units $\left(\mathrm{Fe}-\mathrm{Fe}\right.$ 3.325(3), $\mathrm{Fe}-\mathrm{O}_{\mathrm{CO}}$ 2.009(7), $\left.\mathrm{Fe}^{-} \mu_{3}-\mathrm{O} 1.921(2) \AA\right)$, and the BPDC and BPE linkers (C-C 1.31(2), C-O 1.271(9), C-N 1.29(2) A; C-C-C $\left.124(3), \mathrm{O}-\mathrm{C}-\mathrm{O} 124(2)^{\circ}\right)$ fall within the expected ranges. ${ }^{[11,12]}$

There are four different types of porous tetrahedral units (A-D; Figure 2) in the MOF-500 framework. Tetrahedra A

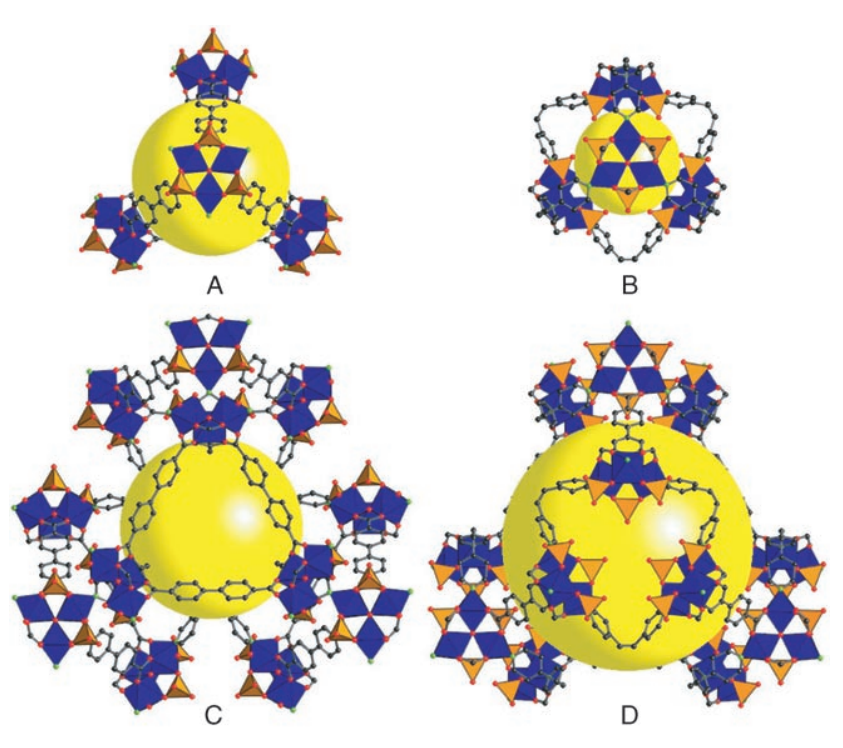

Figure 2. Tetrahedral building blocks A-D of MOF-500. The yellow sphere inside each tetrahedron is the largest sphere that can fit inside the pore without contacting the interior van der Waals surface. Fe blue polyhedra, S orange polyhedra, $\mathrm{O}$ red, $\mathrm{N}$ green, $\mathrm{C}$ gray. Hydrogen atoms and the minor disorder components of the BPDC linkers are omitted.

are the IRMOP-51 building blocks. Tetrahedra B are defined by four iron trimers, each belonging to a separate A-type tetrahedron, linked by six BPE molecules. The cis conformation of the BPE linkers provides the $70.5^{\circ}$ angle necessary to covalently link the iron trimers of adjacent A-type tetrahedra. Tetrahedra $\mathrm{C}$ and $\mathrm{D}$, which encompass the remaining void space, are actually truncated tetrahedra. Both are constructed from the iron-trimer vertices, and the BPDC and BPE edges of the A- and B-type tetrahedra. The BPE linkers protrude into the cavities of the C-type tetrahedra, but not those of the D-type tetrahedra.

The arrangement of the tetrahedral units in MOF-500 corresponds to the high-symmetry $\beta$-cristobalite $\left(\mathrm{SiO}_{2}\right)$ topology: ${ }^{[13]}$ the central $\mu_{3}$-oxygen atoms of each iron trimer serve as the vertices $(\mathrm{X})$ in a cubic $\mathrm{TX}_{2}$ net of corner-sharing $\left\{\mathrm{TX}_{4}\right\}$ tetrahedra. The centers of the A- and B-type tetrahedra (T) are arranged in what can be described as a diamond net, or since there are two types of tetrahedra, as a binary sphalerite (ZnS) net (Figure 3). Note that, as two types of tetrahedra alternate in MOF-500, only nets with evennumbered rings are possible candidates for the topology; in particular, nets with 5-membered rings are ruled out. ${ }^{[5,6 a]}$ The further requirement of $180^{\circ} \mathrm{T}-\mathrm{X}-\mathrm{T}$ angles limits the possible $\mathrm{T}$ nets to either sphalerite or its hexagonal analogue wurtzite. 


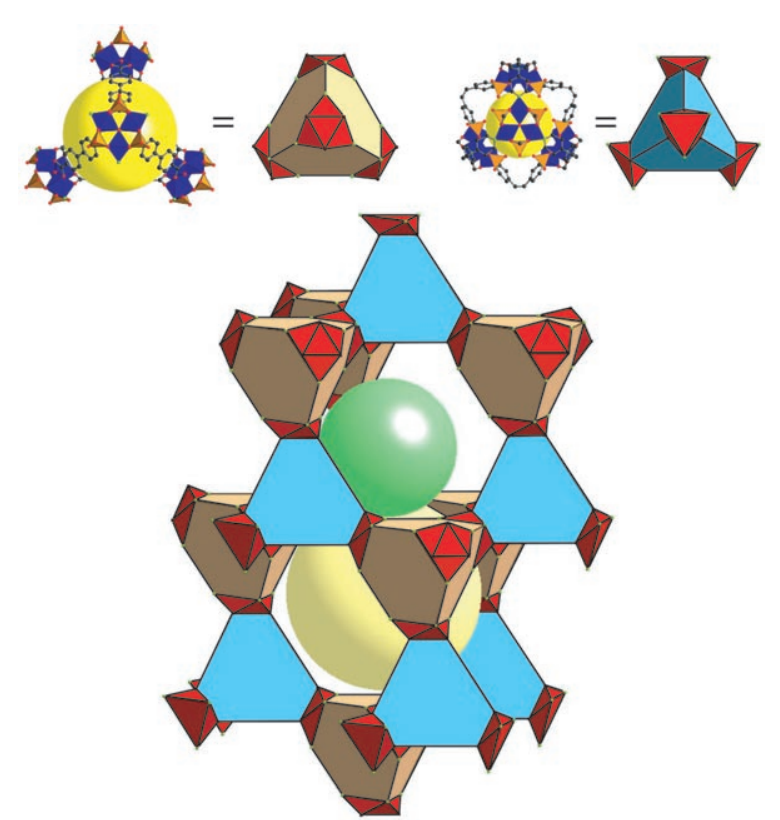

Figure 3. The topology of MOF-500 is based on alternating A-type (brown) and B-type (blue) tetrahedra linked through their shared iron trimers (red). Spheres represent the pore space of tetrahedra C (green) and D (light yellow).

The large cavities of the C- and D-type tetrahedra correspond to the holes delineated by adamantoid cages in the diamond (or sphalerite) net.

The level-3 compound IRMOP-51 crystallizes in two modifications: a stable triclinic form, and a metastable cubic form of much greater specific volume, which provided the inspiration for the present work. Remarkably, the crystal structures of MOF-500 and cubic IRMOP-51 are superimposable and have the same $F \overline{4} 3 m$ symmetry; contractions of only $0.4 \AA$ between adjacent tetrahedra in IRMOP-51 are required for connection to occur in MOF-500 (Figure 4). Correspondingly, the unit-cell lengths of MOF-500 ( $a=$ 38.509(1) ^) and IRMOP-51 ( $a=38.508(9) \AA)$ are virtually identical. However, in MOF-500 the interstitial space of IRMOP-51 has been transformed into a rigid system of interconnected pores that can now be fully accessed by guests. Specifically, in MOF-500, tetrahedra A-D surround four unique pore types, whose properties are summarized in Table 1. The fixed pore diameter (see Table 1 for definition) of tetrahedron A (the IRMOP-51 building block) is maintained at $10.4 \AA$, and the smaller pore of tetrahedron $\mathrm{B}$ has a fixed diameter of $5.2 \AA$; the larger pores of tetrahedra $\mathrm{C}$ and $\mathrm{D}$ have fixed diameters of 13.0 and $18.0 \AA$, respectively. All four types of pore are interconnected by virtue of each tetrahedron having open faces with free pore diameters (see Table 1 for definition) ranging from $3.4 \AA$ for tetrahedron $\mathrm{B}$ to $9.5 \AA$ for tetrahedra C and D. The pores of MOF-500 not only vary in metrics, but also have distinctive chemical environments (Table 1). Organic BPDC linkers and iron trimers line the walls of the A-type pores, whereas BPE linkers and iron trimers, with their sulfate caps facing inwards, line the walls of the B-type pores. Both the C-and D-type pores are lined with BPDC and BPE organic linkers, but only
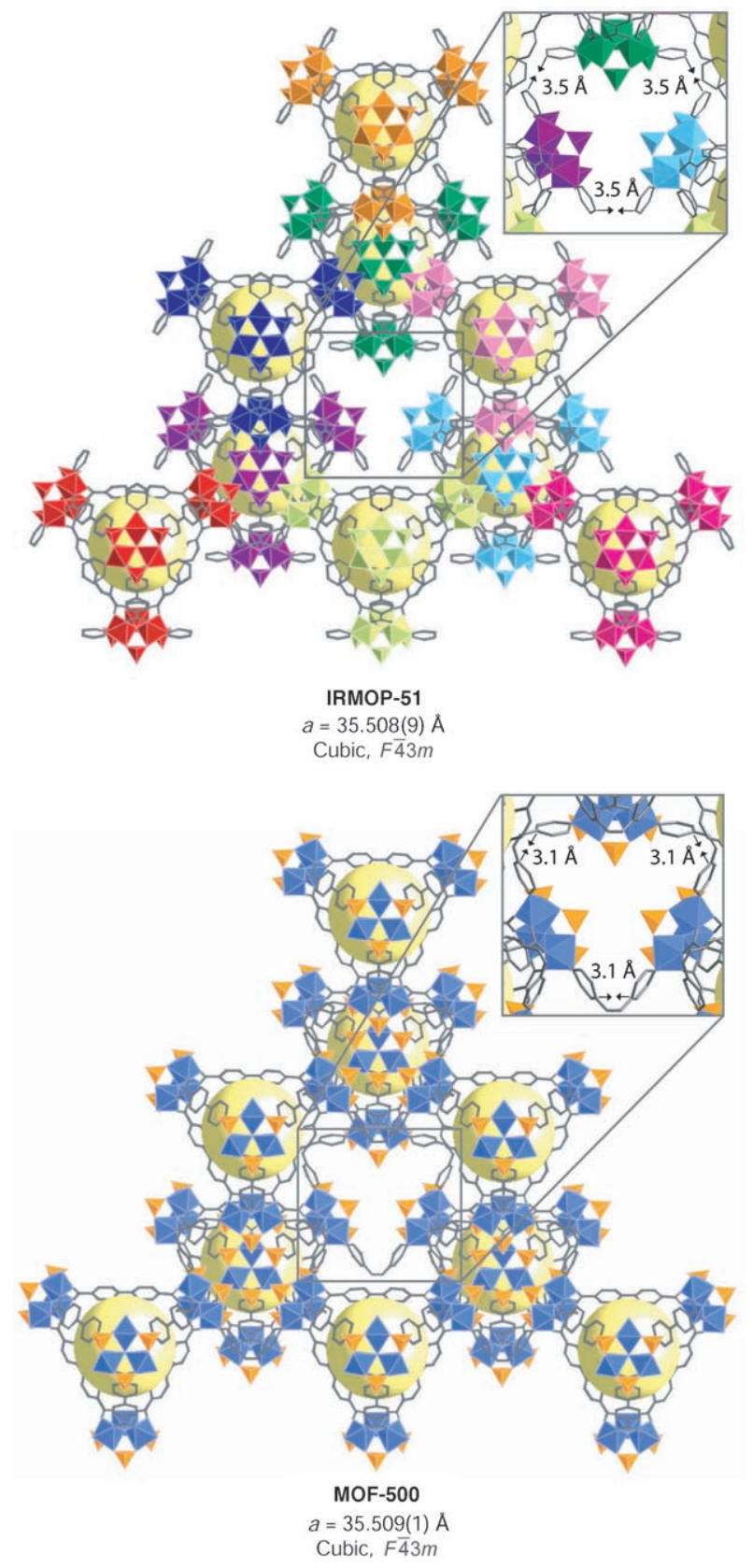

Figure 4. Comparison of the structures of IRMOP-51 and MOF-500, which are nearly isostructural. In IRMOP-51, the individual tetrahedra (each depicted in a different color; Fe and S polyhedra, C gray; yellow spheres represent the tetrahedral pore space) are isolated, but in MOF-500, the A-type tetrahedra (Fe blue polyhedra, S orange polyhedra, $\mathrm{O}$ red, $\mathrm{N}$ green, $\mathrm{C}$ gray; yellow spheres represent the tetrahedral pore space) are linked by BPE molecules, as shown in the enlarged sections of the structures. Hydrogen atoms and the minor disorder components of the BPDC linkers are omitted.

the D-type pores have direct exposure to sulfate units. In the crystals of MOF-500, 78.5\% of the free volume is distributed among the pores in amounts ranging from $6.6 \%$ for B-type pores to $32.4 \%$ for D-type pores (Table 1 ).

Comparison of the gas sorption isotherms for evacuated samples of MOF-500 and cubic IRMOP-51 indicates a significant enhancement in the sorption capacity of MOF- 
Table 1: Properties of the pores in MOF-500.

\begin{tabular}{|c|c|c|c|c|}
\hline \multirow[b]{2}{*}{ Property } & \multicolumn{4}{|c|}{ Pore type } \\
\hline & $A$ & $\mathrm{~B}$ & C & $\mathrm{D}$ \\
\hline Diameter $(\AA ̊), X-$ ray $^{[a, b]}$ & 10.4 & 5.2 & 13.0 & 18.0 \\
\hline Aperture $(\AA), X$-ray ${ }^{[a, c]}$ & 6.4 & 3.4 & 9.5 & 9.5 \\
\hline Fraction of free volume (\%), X-ray ${ }^{[\mathrm{a}, \mathrm{d}]}$ & 15.5 & 6.6 & 24.0 & 32.4 \\
\hline Diameter $(\AA)$, sorption ${ }^{[e]}$ & 9.6 & - & 14.8 & 20.0 \\
\hline \multicolumn{5}{|l|}{ Chemical environment: } \\
\hline $\mathrm{Fe}_{3} \mathrm{O}$ & 4 & 4 & - & - \\
\hline $\mathrm{SO}_{4}$ & - & 12 & - & 12 \\
\hline BPDC & 6 & - & 12 & 6 \\
\hline BPE & - & 6 & 6 & 12 \\
\hline
\end{tabular}

[a] Calculated from the crystal structure of MOF-500 using Cerius ${ }^{2} \cdot{ }^{[16]}$ [b] Fixed pore diameter: the diameter of the largest sphere that can occupy the pore without contacting the van der Waals surface of the framework. [c] Free pore diameter: the diameter of the largest sphere that pass through the aperture of the pore without contacting the van der Waals surface of the framework. [d] Free volume: the free crystal volume bounded by the van der Waals surface of the framework. [e] Calculated from a NLDFT fit to the argon adsorption data for MOF-500 in Figure $5 \mathrm{a}$.

500. The argon sorption isotherms for MOF-500 and IRMOP51 at $87 \mathrm{~K}$ reveal reversible uptakes of 1127 and $278 \mathrm{mg} \mathrm{g}^{-1}$ (at $\left.P / P_{\mathrm{o}}=0.1\right)$, corresponding to 128 and 30 argon atoms per formula unit, respectively (Figure $5 \mathrm{a}$ ). Thus, a fourfold increase in argon sorption capacity is attained by linking IRMOP-51 into a rigid framework. Whereas typical Type-I behavior is observed for IRMOP-51, a distinct reversible step is evident at $P / P_{\mathrm{o}} \approx 0.01$ in the argon and $\mathrm{N}_{2}$ sorption isotherms of MOF-500, followed by a plateau at $P / P_{\mathrm{o}} \gtrsim 0.15$ (see Supporting Information for the $\mathrm{N}_{2}$ sorption isotherm). The specific surface areas $\left(A_{\mathrm{s}}\right)$ of MOF-500 and IRMOP-51, determined by the Brunauer-Emmett-Teller (BET) method using the adsorption branches of the argon isotherms, are 2274 and $544 \mathrm{~m}^{2} \mathrm{~g}^{-1}$, respectively. ${ }^{[14]}$ For MOF-500, $A_{\mathrm{s}}$ represents the cumulative specific surface area for both steps in the micropore region; a similar $A_{\mathrm{s}}$ value of $2224 \mathrm{~m}^{2} \mathrm{~g}^{-1}$ was calculated from the $\mathrm{N}_{2}$ sorption isotherm of MOF-500 at $78 \mathrm{~K}$.

The multistep features observed in the micropore region of both the argon and $\mathrm{N}_{2}$ sorption isotherms of MOF-500 confirm the presence of multiple types of pores, a characteristic known from the crystal structure. To evaluate the pore size distribution of MOF-500, the argon sorption isotherm at $87 \mathrm{~K}$ was analyzed using nonlocal density functional theory (NLDFT) implementing a hybrid kernel for argon adsorption at liquid-argon temperature based on a zeolite/silica model containing cylindrical pores. ${ }^{[15]}$ The distribution calculated by fitting the MOF-500 adsorption data revealed three types of pores with widths centered around 9.6, 14.8, and $20.0 \AA$ (Figure $5 \mathrm{~b}$, histogram). Moreover, these values are consistent with the dimensions of pores A, C, and D in the MOF-500 crystal structure (Table 1 ). The contribution from pore $\mathrm{B}$ is not observed, because its pore aperture $(3.4 \AA)$ is very similar in size to the kinetic diameter of argon $(3.4 \AA) \cdot{ }^{[14]}$ Further analysis of the pore size distribution reveals that the contribution of micropores (widths $<20 \AA$ ) to the total pore volume is $0.61 \mathrm{~cm}^{3} \mathrm{~g}^{-1}$ or $65 \%$ (Figure $5 \mathrm{~b}$, curve), which compares favorably to the sum of the free volumes in pores A, $\mathrm{C}$, and $\mathrm{D}(72 \%)$. The value of $0.61 \mathrm{~cm}^{3} \mathrm{~g}^{-1}$, however, is in
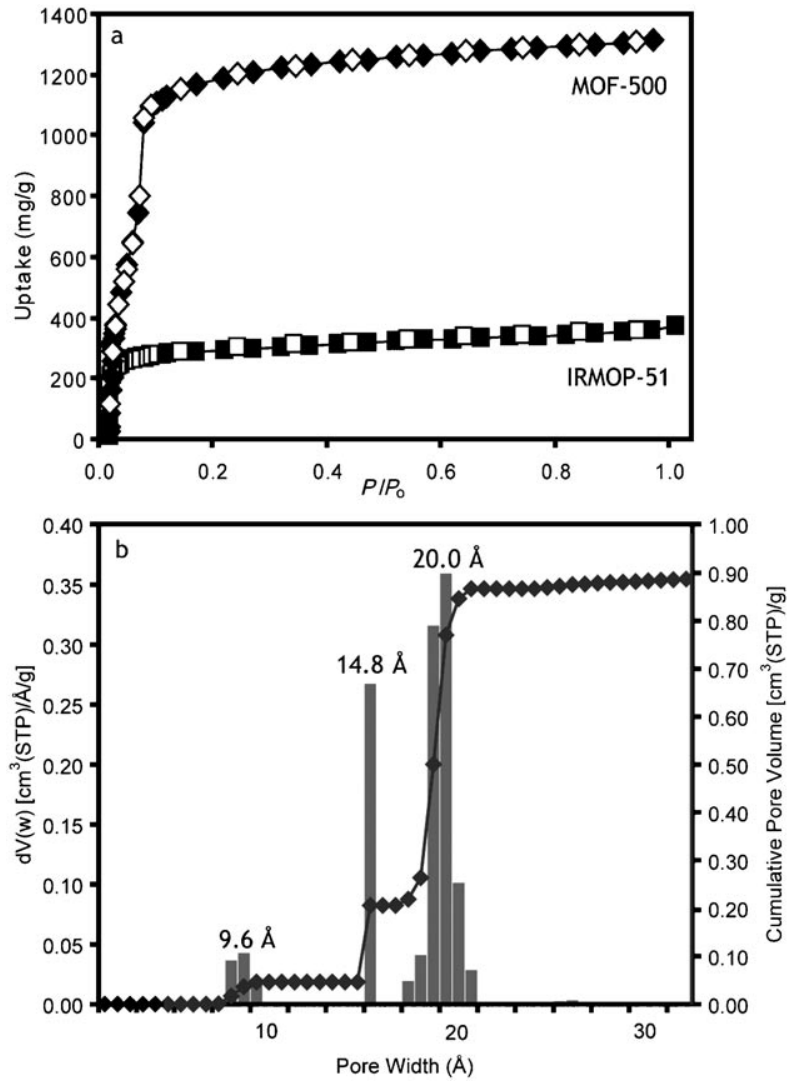

Figure 5. a) Argon sorption isotherms for MOF-500 $(\diamond, \diamond)$ and IRMOP-51 ( $\mathbf{\square}, \square)$ at $87 \mathrm{~K}$ (filled symbols: adsorption, open symbols: desorption). b) Pore size distribution (left axis, histogram) and cumulative pore volume (right axis, $\bullet$ ) for MOF-500, calculated from a NLDFT fit to the argon adsorption data for MOF-500 in (a). See text for details. STP $=$ normalized to standard temperature and pressure.

excellent agreement with the value of $0.63 \mathrm{~cm}^{3} \mathrm{~g}^{-1}$ derived from a Dubinin-Radushkevich (DR) treatment of the argon sorption isotherm. In contrast, a DR analysis of the IRMOP51 argon sorption isotherm yielded a micropore volume of only $0.15 \mathrm{~cm}^{3} \mathrm{~g}^{-1}$. The sorption data validate the accessibility and permanently porous nature of three types of cavities in MOF-500, while only one type of cavity was identified for MOF-500.

This study illustrates at least two unique features of MOF500: 1) conceptually, its structure is built up from four levels of hierarchy, and 2) its sorption capacity is significantly enhanced relative to that of its level-3 building units (IRMOP-51). The general applicability of this hierarchical approach to solid-state synthesis is virtually unlimited, given the large number of crystalline molecular solids.

Received: January 16, 2006

Keywords: iron - metal-organic frameworks . microporous materials · nanostructures · sorption 
[1] a) D. T. Bong, T. D. Clark, J. R. Granja, M. R. Ghadiri, Angew. Chem. 2001, 113, 1016-1041; Angew. Chem. Int. Ed. 2001, 40, 988-1011; b) S. I. Stupp, V. Le Bonheur, K. Walker, L. S. Li, K. E. Huggins, M. Keser, A. Amstutz, Science 1997, 276, $384-$ 389; c) V. Berl, M. J. Krische, I. Huc, J.-M. Lehn, M. Schmutz, Chem. Eur. J. 2000, 6, 1938-1946; d) M. C. T. Fyfe, J. F. Stoddart, Acc. Chem. Res. 1997, 30, $393-401$; e) D. Zhao, J. S. Moore, Chem. Commun. 2003, 807-818; f) M. Fujita, D. Oguro, M. Miyazawa, H. Oka, Nature 1995, 378, 469-471; g) N. I Kovtyukhova, T. E. Mallouk, Chem. Eur. J. 2002, 8, 4355-4363; h) T. K. Holman, A. M. Pivovar, M. D. Ward, Science 2001, 294 , 1907-1911; i) M. W. Hosseini, Acc. Chem. Res. 2005, 38, $313-$ 323.

[2] A. C. Sudik, A. W. Millward, N. W. Ockwig, A. P. Côté, J. Kim, O. M. Yaghi, J. Am. Chem. Soc. 2005, 127, 7110-7118.

[3] G. Férey, J. Solid State Chem. 2000, 152, 37-48.

[4] A. C. Sudik, A. P. Côté, O. M. Yaghi, Inorg. Chem. 2005, 44, 2998-3000.

[5] C. Serre, F. Millange, S. Surblé, G. Férey, Angew. Chem. 2004 116, 6445-6449; Angew. Chem. Int. Ed. 2004, 43, 6285-6289.

[6] a) G. Férey, C. Mellot-Draznieks, C. Serre, F. Millange, Acc. Chem. Res. 2005, 38, 217-225; b) G. Férey, C. Serre, C. MellotDraznieks, F. Millange, S. Surblé, J. Dutour, I. Margiolaki, Angew. Chem. 2004, 116, 6456-6461; Angew. Chem. Int. Ed. 2004, 43, 6296-6301; c) C. Mellot-Draznieks, J. Dutour, G. Férey, Z. Anorg. Allg. Chem. 2004, 630, 2599-2604.

[7] MOF-500: refined formula: $\mathrm{Fe}_{12} \mathrm{~S}_{12} \mathrm{C}_{156} \mathrm{H}_{96} \mathrm{~N}_{12} \mathrm{O}_{86.61}$ (see Supporting Information for details), $T=258(2) \mathrm{K}$, cubic, space group $F \overline{4} 3 m$ (No. 216), $a=38.509$ (1) $\AA, V=57107(3) \AA^{3}, Z=4, \rho_{\text {calcd }}=$ $0.533 \mathrm{~g} \mathrm{~cm}^{-3}, \mu\left(\mathrm{Mo}_{\mathrm{Ka}}\right)=0.372 \mathrm{~mm}^{-1}, 72106$ measured reflections, 2889 unique reflections $\left(R_{\text {int }}=0.4268\right), 128$ parameters, no restraints, $R_{1}=0.1005$ for 1721 observed reflections $(I>$ $2 \sigma(I)), w R_{2}($ all data $)=0.2598, S=1.062, \Delta \rho_{\text {elec }}=0.407 \mathrm{e}^{-3}$. CCDC-294671 (MOF-500) contains the supplementary crystallographic data (and details of the data handling and structure refinement) for this paper. These data can be obtained free of charge from The Cambridge Crystallographic Data Centre via www.ccdc.cam.ac.uk/data_request/cif.

[8] D. D. Perrin, W. L. F. Armarego, Purification of Laboratory Chemicals, 3rd ed. Pergamon, Oxford, 1988.

[9] a) M. E. Kosal, J.-H. Chou, S. R. Wilson, K. S. Suslick, Nat. Mater. 2002, 1, 118-121; b) G. J. McManus, Z. Wang, M. Zaworotko, Cryst. Growth Des. 2004, 4, 11-13; c) D. J. Hoffart, S. J. Loeb, Angew. Chem. 2005, 117, 923-926; Angew. Chem. Int. Ed. 2005, 44, 901-904; d) B. D. Chandler, A. P. Côté, D. T. Cramb, J. T. Hill, G. K. H. Shimizu, Chem. Commun. 2002, 1900-1901; e) H. K. Chae, D. Y. Siberio-Pérez, J. Kim, Y. Go, M. Eddaoudi, A. J. Matzger, M. O'Keeffe O. M. Yaghi, Nature 2004, 427, 523-527.

[10] a) H. Li, M. Eddaoudi, M. O'Keeffe, O. M. Yaghi, Nature 1999, 402, 276-279; b) M. Eddaoudi, D. B. Moler, H. Li, B. Chen, T. M. Reineke, M. O'Keeffe, O. M. Yaghi, Acc. Chem. Res. 2001, 34, 319-330.

[11] R. D. Cannon, R. P. White, Prog. Inorg. Chem. 1988, 36, $195-$ 298.

[12] F. H. Allen, O. Kennard, D. G. Watson, L. Brammer, G. Orpen, J. Chem. Soc. Perkin Trans. 2 1987, S1-S19. Note, the elevated uncertainties for the geometric parameters of the BPE and BPDC linkers are primarily due to disorder.

[13] M. O'Keeffe, B. G. Hyde, Crystal Structures: I. Patterns and Symmetry, Mineralogical Society of America, Washington DC, 1996.

[14] F. Rouquerol, J. Rouquerol, K. S. W. Sing, Adsorption by Powder and Porous Solids, Academic Press, London, 1999.

[15] a) J. P. Olivier, W. B. Conklin, M. Szombathely in Characterization of Porous Solids III (Eds.: F. Rodriguez-Reinoso, J.
Rouquerol, K. S. W. Sing, K. K. Unger), Elsevier, Amsterdam, 1994, pp. 81-89; b) P. I. Ravikovitch, D. Wei, W. T. Chueh, G. L. Haller, A. V. Neimark, J. Phys. Chem. B 1997, 101, 3671-3679.

[16] Cerius ${ }^{2}$ Modeling Environment, Molecular Simulations Inc., San Diego CA, 1999. 